\title{
A report on gender diversity and equality in the geosciences: an analysis of the Swiss Geoscience Meetings from 2003 to 2019
}

\author{
FRANCESCA PICCOLI ${ }^{1}$ AND GIULIA GUIDOBALDI ${ }^{2}$ \\ ${ }^{1}$ University of Bern \\ ${ }^{2}$ Labor Für Ionenstrahlphysik (LIP) \\ Presenting Author: francesca.piccoli@geo.unibe.ch
}

Data collection and elaboration is essential for the monitoring of gender diversity and equality in the academic environment. In our study[1], we focused on the evolution of gender distribution in the geosciences by analyzing the participation data of the Swiss Geoscience Meeting (SGM), held every year since 2003. We built a 17 years long dataset, which contains information about gender and academic stage of participants. Gender distribution was evaluated for scientific contributions (e.g., talk and poster), and for decision making positions (e.g., conveners and committee members).

Over the last 17 years, the presence of women at the SGM has steadily increased, currently attesting around $30 \%$ of the total participants. Nevertheless, a relevant fraction of the female participants is represented by students, while female scientists are often less than $25 \%$. This suggests a significant drop out of female academics shortly after the PhD. Despite the increase of women students in geosciences in Switzerland, the analysis of gender distribution among participants at different sessions suggests that horizontal gender segregation still persists in the geosciences. In addition, we found that men outnumber women in decision making positions, such as committee members, and as invited speaker for the plenary sessions. Lastly, the analysis of seven prizes awarded by different geological societies shows that, in some cases, women are less likely to be nominated for awards.

Overall, the analysis of the 17 years dataset of the SGM reveals a positive trend towards a more inclusive environment in the geosciences. However, it also shows that prominent vertical and horizontal gender segregation still persists in the geosciences. We conclude that particular attention has to be focused on the early stages of women academic careers. We also suggest that diversifying gender distribution among conveners and plenary lecture speakers is a good practice to offer more diverse role models to undergraduate students and junior scientists and, potentially, overcome career- and study fieldrelated gender imbalance.

[1] Piccoli, F. \& Guidobaldi, G. A report on gender diversity and equality in the geosciences: an analysis of the Swiss Geoscience Meetings from 2003 to 2019. Swiss Journal of Geosciences 114, 1-12 (2021). 